\title{
Effects of Guanethidine, Reserpine, and Methyldopa on Reflex Venous and Arterial Constriction in Man *
}

\author{
Dean T. Mason and Eugene Braunwald with the technical assistance of \\ Diane D. Krueger, Clara V. King, and Richard B. Karsh
}

(From the Cardiology Branch, National Heart Institute, Bethesda, Md.)

The precise mechanisms by which guanethidine, reserpine and methyldopa lower arterial pressure in patients with hypertension are not clear. In the past, in characterizing the circulatory action of drugs, major emphasis has been placed on their effects upon the heart and arteriolar bed, but less attention has been directed to their possible influence on venous tone. The importance of changes in venous tone in circulatory regulation is well established, and reflexes mediated through the sympathetic nervous system are clearly important determinants of venous tone (1-5). It was recently demonstrated in anesthetized, openchest dogs that large doses of guanethidine and reserpine are capable of blocking the reflex venoconstriction that occurs during carotid arterial occlusion or central vagal stimulation (6). The possibility has been considered that blockade of reflex venoconstriction may also play a role in the clinical action of these and other antihypertensive drugs (5, 7-12). Accordingly, this investigation was undertaken to determine the effects of guanethidine, reserpine, and methyldopa, when given to human subjects in the doses commonly employed clinically, on reflex regulation of forearm venous tone. In the course of the studies the actions of these drugs on reflex regulation of the arteriolar bed of the forearm were also elucidated.

\section{Methods}

A total of 17 normal, normotensive, male volunteer subjects was studied. With the exception of two subjects, who were 33 and 38 years old, they ranged in age between 18 and 28 years. Multiple studies with more than one drug were carried out in 3 of the subjects. Immediately after the initial study, which will be referred to as the "predrug control study," drug administration was begun. Guanethidine ${ }^{1}$ was given to 10 sub-

* Submitted for publication November 27, 1963; accepted March 6, 1964.

1 Obtained from Ciba Pharmaceutical Company, Summit, N. J. jects in daily oral doses beginning with $10 \mathrm{mg}$ and was increased in a stepwise fashion to maximal doses of between 30 and $50 \mathrm{mg}$ per day (average $=43 \mathrm{mg}$ per day). The duration of drug administration ranged from 26 to 43 and averaged 35 days. After this period of drug administration, a second study, which will be referred to as the "drug study," was carried out. After this study guanethidine was discontinued, and in 8 of the 10 subjects a third study, which will be referred to as the "postdrug control study," was carried out 21 to 42 days later.

Reserpine ${ }^{1}$ was given to 7 subjects in two oral doses daily. The initial daily dose was $0.25 \mathrm{mg}$, and after several days it was increased to $0.50 \mathrm{mg}$ per day. The duration of drug administration ranged from 35 to 132 and averaged 68 days. After the drug study reserpine was discontinued, and in 5 subjects a postdrug control study was carried out 21 to 56 days later.

Methyldopa ${ }^{2}$ was administered to 5 subjects in four oral doses daily. The initial daily dose was $0.5 \mathrm{~g}$, and it was increased in stepwise fashion to maximal doses ranging from 2.0 to $5.0 \mathrm{~g}$ per day (average $=3.0 \mathrm{~g}$ per day). The duration of drug administration ranged from 21 to 49 and averaged 31 days. A postdrug control study was carried out in 3 subjects 21 to 56 days after discontinuation of the drug.

In all subjects the drug was administered in a manner so that the maximal dose was given without the presence of serious postural hypotension or of particularly annoying side effects such as fatigue or nasal congestion. The arterial blood pressure was measured sphygmomanometrically four times daily with the subjects in the supine and the erect positions. In each subject the arterial pressure in the erect position fell during drug administration, but whenever the systolic pressure in the erect position fell to below $90 \mathrm{~mm} \mathrm{Hg}$, the drug was omitted, or the dosage was temporarily lowered. At 8 a.m. on the day of the drug study, the subjects who received guanethidine exhibited an average fall in systolic arterial pressure of $23.8 \pm 2.8 \mathrm{~mm} \mathrm{Hg}$ (standard error of the mean). The fall in systolic arterial pressure in the subjects receiving reserpine averaged $11.1 \pm 1.3 \mathrm{~mm} \mathrm{Hg}$; that in the subjects on methyldopa averaged $23.6 \pm 2.5 \mathrm{~mm} \mathrm{Hg}$.

The response of the vascular bed of the forearm to the immersion of the opposite hand into ice water for 1

2 Obtained from Merck Sharp \& Dohme, West Point, $\mathrm{Pa}$. 
to 2 minutes was determined in all subjects studied. In addition, in each study the Valsalva maneuver was carried out by maintaining an expiratory pressure of $40 \mathrm{~mm}$ $\mathrm{Hg}$ for 10 seconds while systemic arterial pressure was recorded. In 4 subjects, the effects of $2.0 \mathrm{mg}$ atropine on the response of the forearm to immersion of the opposite hand in ice water were determined at the time of the drug study. In 9 subjects the responses to strenuous leg exercise were assessed. In the latter studies the subjects pedaled a bicycle ergometer, performing 1,400 foot-pounds per minute for 6 minutes. Measurements of arterial pressure and of forearm blood flow and venous tone were carried out immediately after discontinuation of the exercise.

A plethysmographic technique was employed for the measurement of forearm blood flow and the estimation of forearm venous tone. This technique has been described in detail elsewhere (13). Changes in forearm volume were determined by placing the Whitney mercury-in-rubber strain gauge plethysmograph (14) on the mid-forearm. Forearm venous pressure was measured through a $14-\mathrm{cm} \mathrm{PE}$ no. 50 catheter introduced into a large vein at the wrist and advanced so that its tip lay just distal to the mercury-in-rubber gauge. The forearm was elevated so that the venous pressure was exactly zero.

A sphygmomanometric cuff was placed around the wrist and inflated to a level exceeding systolic arterial pressure just before each venous occlusion. A $13-\mathrm{cm}$ sphygmomanometric cuff was placed around the upper arm, and forearm venous occlusion was produced by suddenly inflating this cuff to a pressure below the diastolic arterial pressure. Arterial pressure was measured through an indwelling arterial needle placed into the brachial artery of the opposite forearm.

Forearm blood flow was calculated from the change in forearm circumference during venous occlusion $(14,15)$ and expressed as milliliters per $100 \mathrm{~g}$ tissue per minute. Forearm vascular resistance was calculated as the ratio of mean arterial pressure to forearm blood flow and was expressed in units of millimeters $\mathrm{Hg}$ /milliliters per 100 $\mathrm{g}$ per minute. The pressure-volume characteristics of the capacitance vessels, expressed in units of millimeters $\mathrm{Hg}$ per milliliter, were calculated by determining the ratio of the increment in venous pressure to the increment in forearm volume that occurred after inflation of the venous occlusion cuff. Venous pressure and volume were measured 10 seconds after the venous occlusion (Figures 1 and 2). Since both pressure and volume rose in an almost linear fashion immediately after occlusion, this ratio was not altered significantly by the precise time, during the first 30 seconds after occlusion, at which the measurements were made. This ratio has also been used by Sharpey-Schafer to express the pressure-volume characteristics of the venous bed (16).

To determine the reproducibility of the measurements when made on different days, control studies were carried out on 6 additional subjects. Measurements of arterial pressure, forearm blood flow, and venous tone by the acute occlusion method were made in the basal state and after cold stimulation on 2 different days that were up to 20 days apart.

In 4 subjects, two venous catheters were employed; one catheter was introduced into a vein on the ulnar and the other into a vein on the radial aspect of the wrist. No observable differences were noted in venous tone calculated from the increment in venous pressure that occurred in either vein (Figures 1 and 2 ).

In 5 subjects venous tone was measured by two equilibration techniques in addition to the acute occlusion method. With both equilibration techniques the forearm was elevated so that the venous pressure fell to zero, and the wrist cuff was inflated to suprasystolic levels. In the first method the venous occlusion cuff was suddenly inflated to $30 \mathrm{~mm} \mathrm{Hg}$, and venous pressure and forearm circumference were permitted to equilibrate for 2 minutes. Venous tone was calculated by the increments in volume and pressure that had taken place after the full 2-minute period. The second of these techniques is a modification of the stepwise venous occlusion method described by Wood and Eckstein (17), in which the venous occlusion cuff is inflated by $5-\mathrm{mm}$ increments to $30 \mathrm{~mm} \mathrm{Hg}$. Sufficient time was permitted to elapse between each of these stepwise inflations for the venous pressure and forearm circumference to reach stable values.

The data were analyzed for statistical significance by Student's $t$ test. Probability values below 0.05 were regarded as significant (18).

\section{Results}

Reproducibility. The reproducibility of the basal measurements and of the response to cold stimulation in the same subject on different days without the administration of any drug is shown in Table I. No consistent or significant changes in the basal values between the two studies were noted. During cold stimulation significant increases in arterial pressure, forearm vascular resistance, and venous tone were observed ( $p<$ 0.01 ), but the change in forearm blood flow was not significant statistically. There were no consistent or significant changes in the responses to cold stimulation between the two studies.

Guanethidine. During the predrug control study the basal mean arterial pressure averaged $88 \pm 3.5 \mathrm{~mm} \mathrm{Hg}$ (SEM). At the time of the drug study the pressure averaged $83 \pm 2.8 \mathrm{~mm}$ $\mathrm{Hg}$, and $82 \pm 3.2 \mathrm{~mm} \mathrm{Hg}$ at the time of the postdrug control study. The resting heart rate averaged $70 \pm 2.9$ per minute during the control study. It was significantly slower, $58 \pm 2.4$ per minute $(p<0.01)$, during the drug study. At 


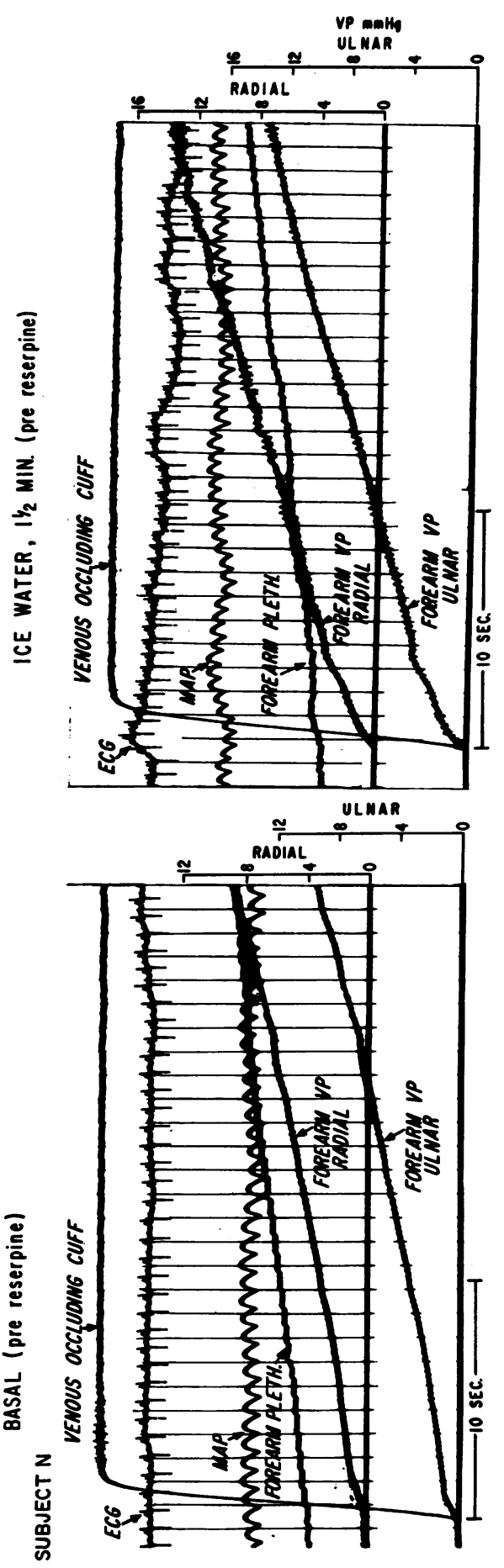

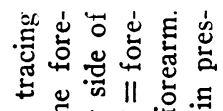
†

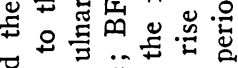

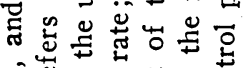

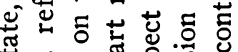

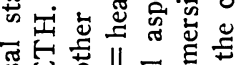

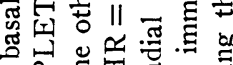

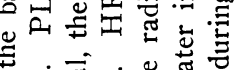

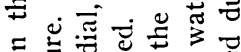

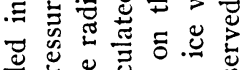

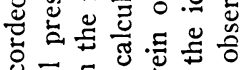
㻖

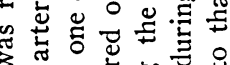

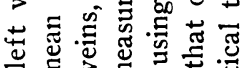

‡11

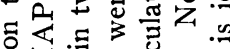

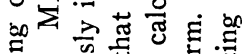

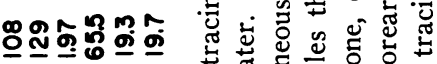
$1 \uparrow 111$

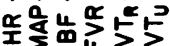
111 ํํำํำํํำํํำ

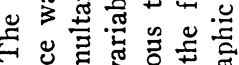

.

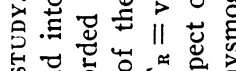

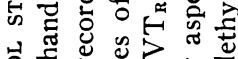

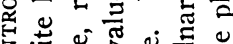

解势

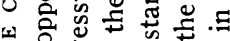

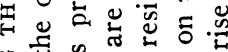

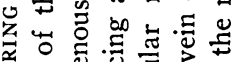

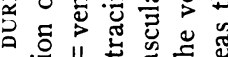

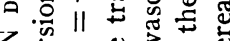

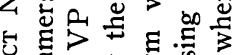

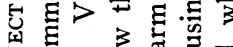

品.

云苋焉

\%

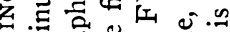

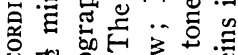

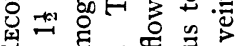

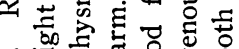

-

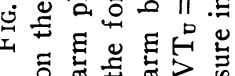




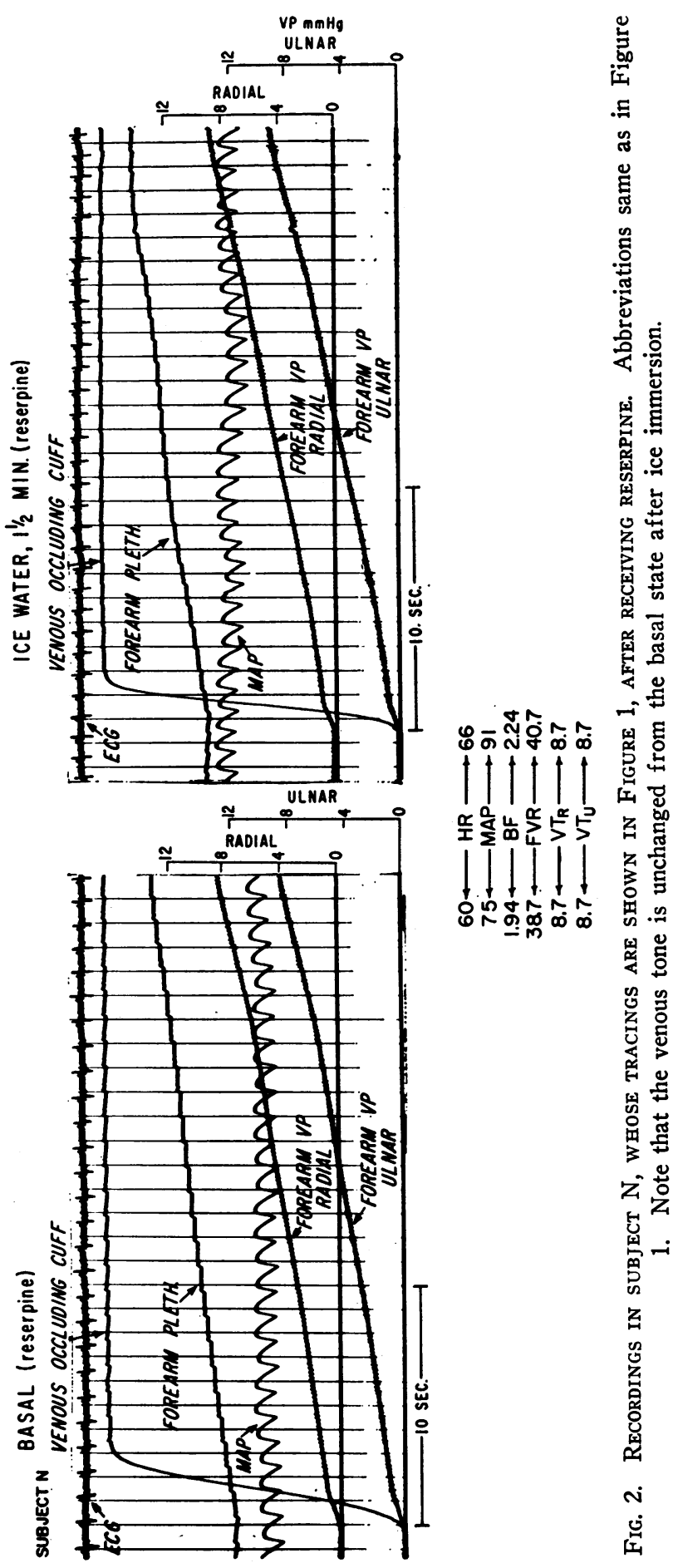


TABLE I

Comparison of two control measurements and of responses to cold stimulation on separate days in the absence of drug administration*

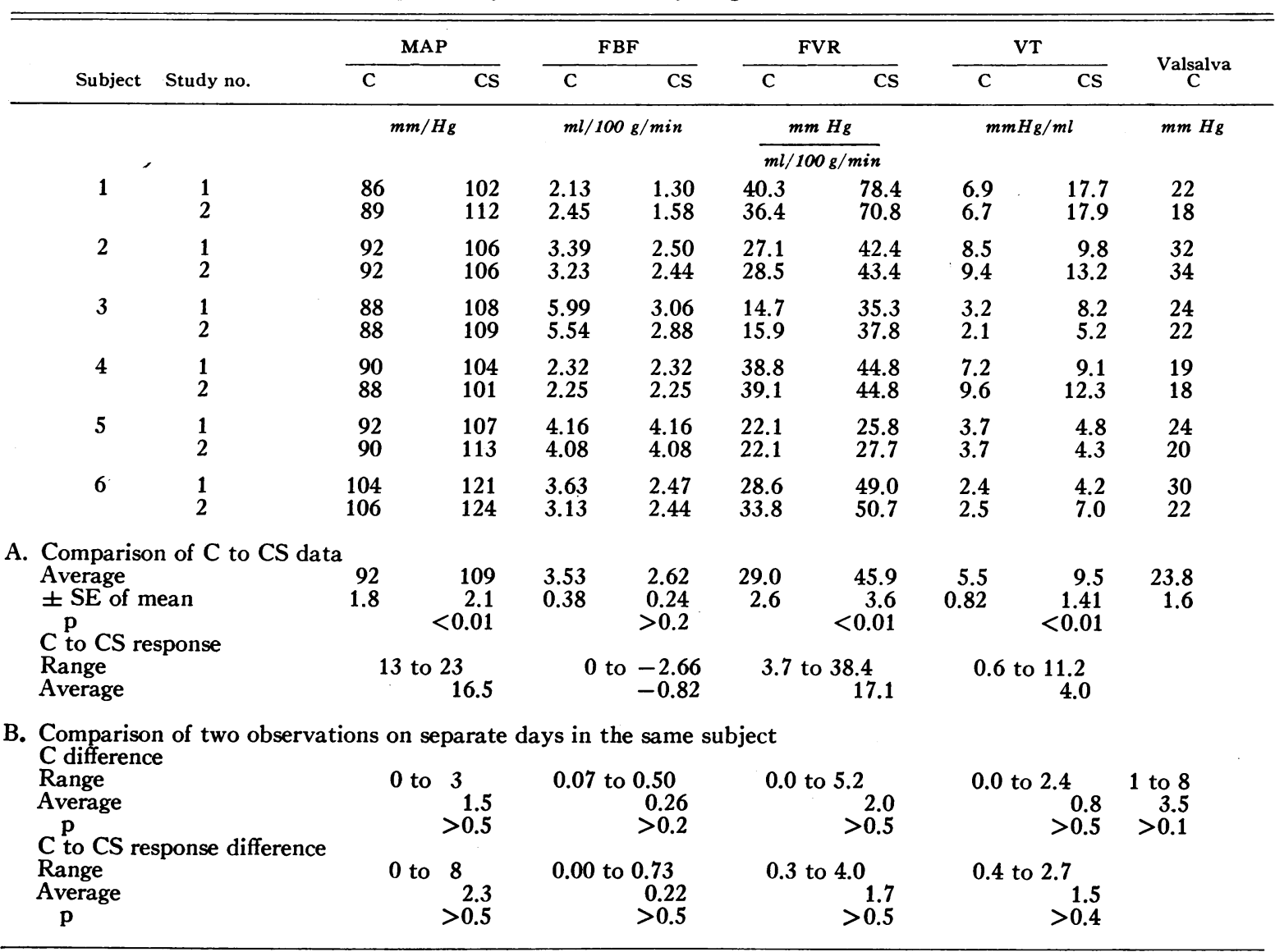

${ }^{*} \mathrm{C}=$ control data $; \mathrm{CS}=$ observation made during cold stimulation. Study no. 1 = first study; $2=$ second study. $\mathrm{MAP}=$ mean arterial pressure; $\mathrm{FBF}=$ forearm blood flow $; \mathrm{FVR}=$ forearm vascular resistance $; \mathrm{VT}=$ venous tone (acute occlusion technique); Valsalva = post-Valsalva overshoot of systolic arterial pressure.

A. Comparison of $\mathrm{C}$ to CS data presents the changes produced by cold stimulation, their statistical significance, and the range and average level of the response. B. Comparison of two observations in the same subject represents the variability of the control values and of the responses to cold stimulation when the measurements were carried out on 2 separate days.

the time of the postdrug control study the heart rate was significantly more rapid than at the time of the drug study, averaging $65 \pm 4.3$ per minute $(\mathrm{p}<0.01)$.

When measured in the basal state before leg exercise or immersion of the opposite hand in ice water, the venous tone, measured by the acute occlusion technique, was slightly but significantly $(p<0.01)$ lower during the drug study than at the time of the predrug control observations (Figure $3 \mathrm{~A})$. During the drug study the increase in venous tone produced by cold immersion was markedly decreased in 2 subjects and abolished in 5 subjects; a paradoxical decline in venous tone occurred in 3 subjects. During the postdrug control study venoconstriction again occurred during cold immersion in all 8 subjects (Figure 3B). In the subject in whom venous tone was determined by the equilibration techniques, an increase in venous tone occurred during cold immersion in the predrug control study, but this increase was found to have been abolished during the drug study (Figures 4 and 5).

Leg exercise in 5 subjects resulted in an increase in venous tone, measured by the acute occlusion technique, which averaged $2.3 \pm 1.0 \mathrm{~mm}$ $\mathrm{Hg}$ per ml during the predrug control study. During the drug study this increase in venous tone 


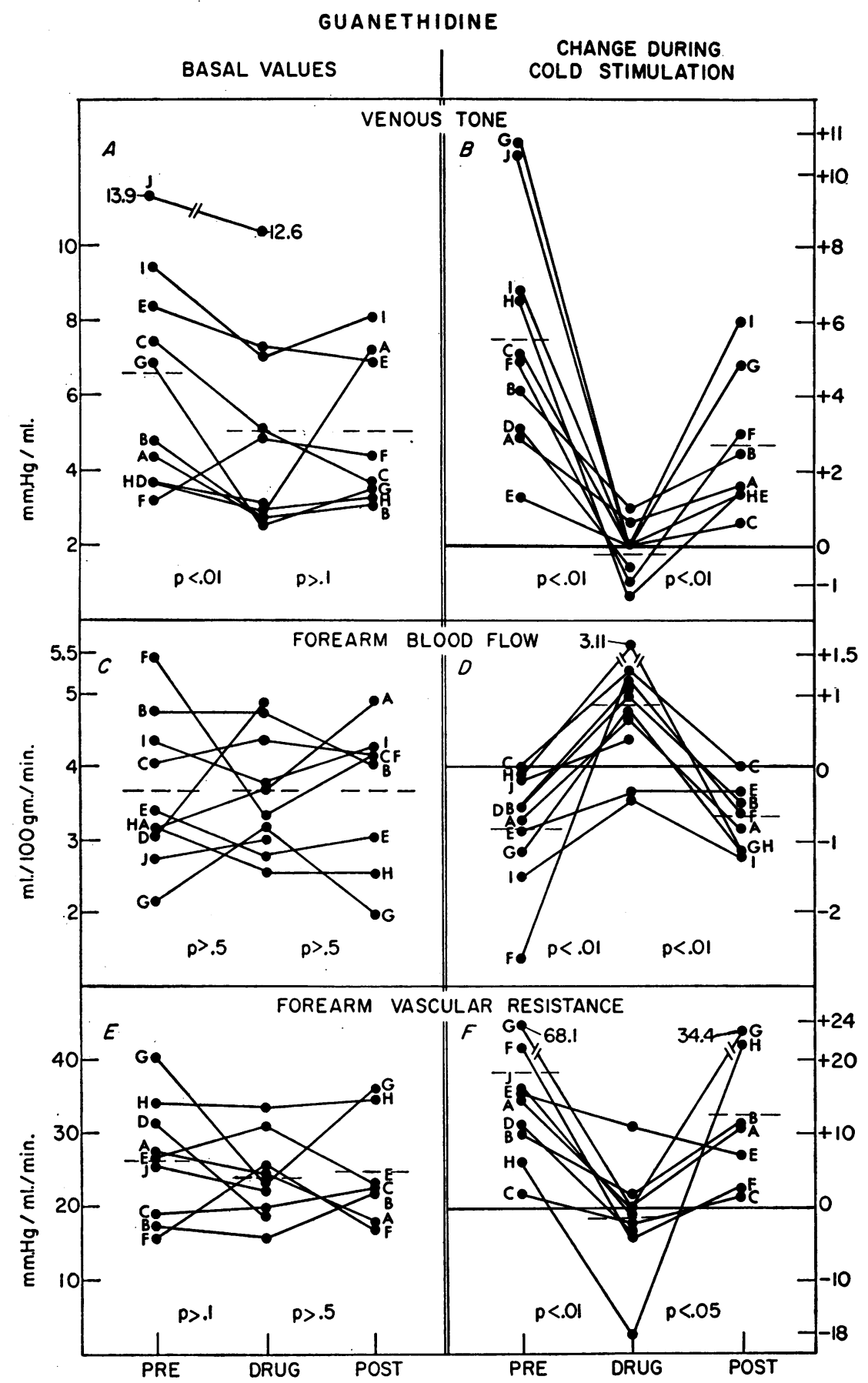

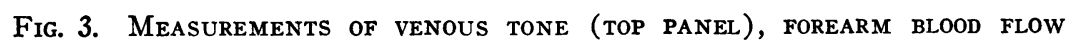
(CENTER PANEL), AND FOREARM VASCULAR RESISTANCE (BOTTOM PANEL) IN SUBJECTS BEFORE (PRE), DURING (DRUG), AND AFTER DISCONTINUATION (POST) OF GUANETHidine. Measurements in the basal state are on the left, and the changes occurring during cold stimulation are on the right. In each instance the mean value is indicated by the broken horizontal line. Each subject is designated by a different letter placed next to the experimental data in this and all subsequent figures. 
produced by leg exercise was abolished in all subjects, and the average change was a fall that averaged $1.5 \pm 0.7 \mathrm{~mm} \mathrm{Hg}$ per $\mathrm{ml}$.
During the drug study the decline in forearm blood flow that occurred before administration of drug was diminished or reversed (Figure 3D).

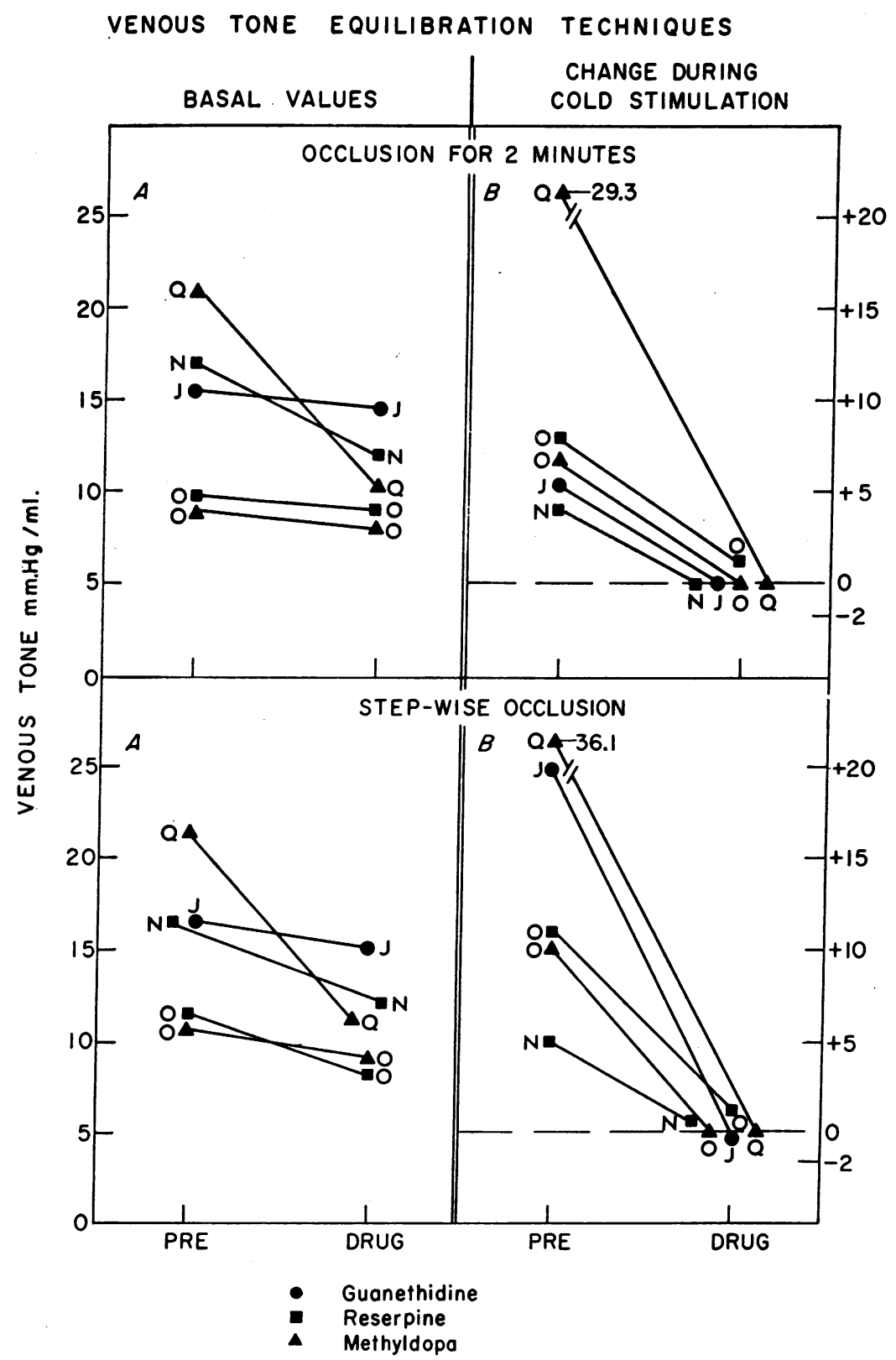

Fig. 4. Results of measurements of venous tone by the two eQUiliBRATION TECHNIQUES DESCRIBED IN THE TEXT. The top panel shows the data obtained by the technique in which a pressure of $30 \mathrm{~mm} \mathrm{Hg}$ was maintained in the occlusive cuff for 2 minutes; the bottom panel shows the value for venous tone calculated at an occlusive pressure of $30 \mathrm{~mm} \mathrm{Hg}$ obtained by the stepwise occlusion method (19). Measurements in the basal state are on the left, and the changes occurring during cold stimulation are on the right. Note that in all 5 patients studied by the equilibration methods, the increase in venous tone during cold immersion was abolished. 
Similarly, the increase in forearm vascular resistance that occurred during the control study was either diminished or abolished or a paradoxical decline in resistance occurred during cold im- mersion (Figure 3F). In 5 subjects, leg exercise resulted in an increase of calculated forearm vascular resistance that averaged $7.5 \pm 3.8 \mathrm{~mm}$ $\mathrm{Hg}$ per $\mathrm{ml}$ per minute during the predrug control

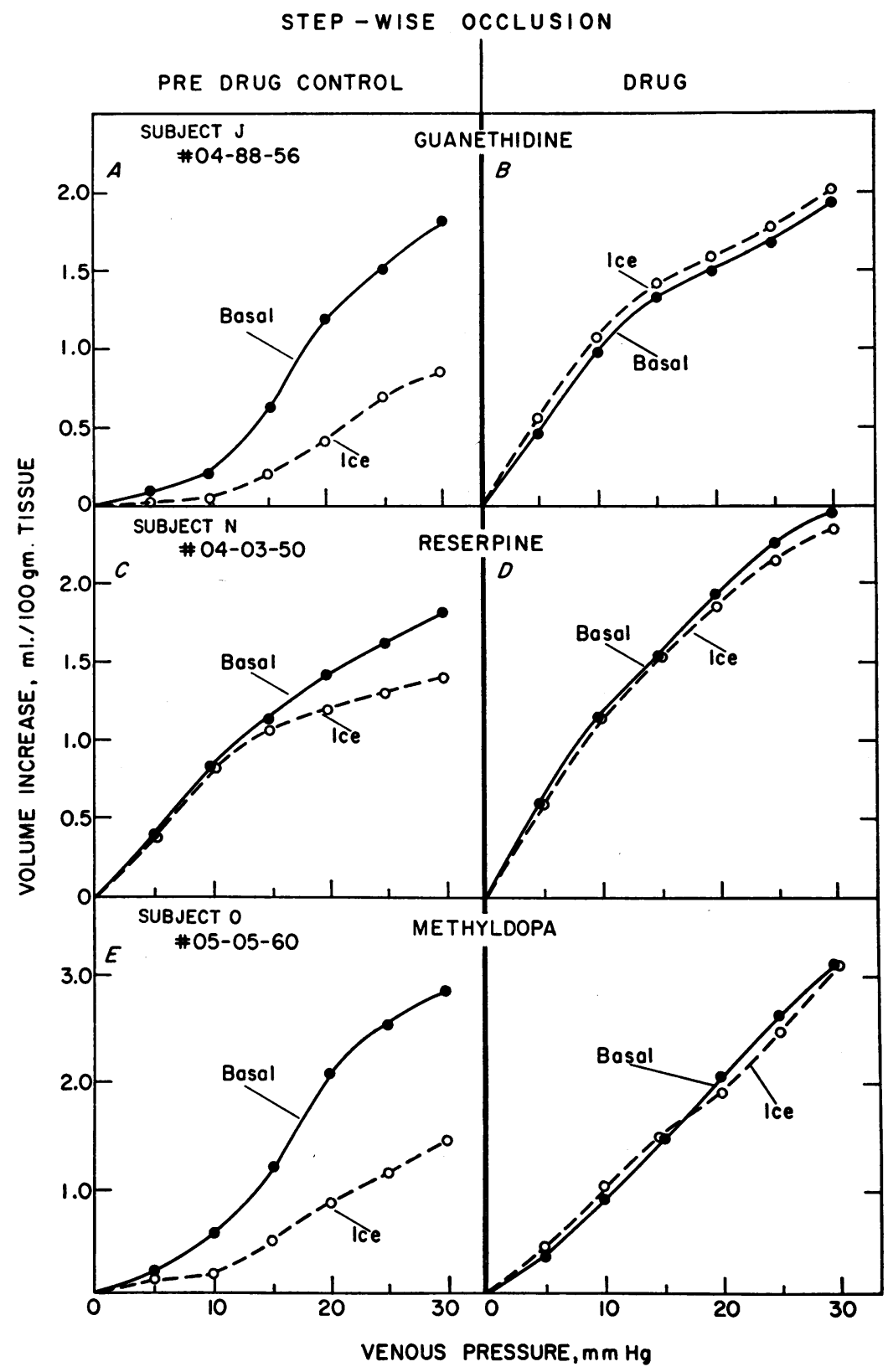

Fig. 5. EFFECTS OF GUANETHIDINE, RESERPINE, AND METHYLDOPA ON THE RESPONSE OF VENOUS PRESSURE-VOLUME CURVES TO COLD IMMERSION, AS STUDIED BY THE STEPWISE OCCLUSION METHOD. The venous pressure-volume curves in the basal state are shown as the solid lines connecting the dots; those obtained during cold immersion are represented by the broken lines connecting the open circles. The predrug control studies are on the left, and the drug studies are on the right. 
study. At the time of the drug study the in- minute, a value significantly $(p<0.02)$ lower crease in forearm vascular resistance during leg than that observed during the predrug control exercise averaged $3.5 \pm 3.1 \mathrm{~mm} \mathrm{Hg}$ per $\mathrm{ml}$ per study.

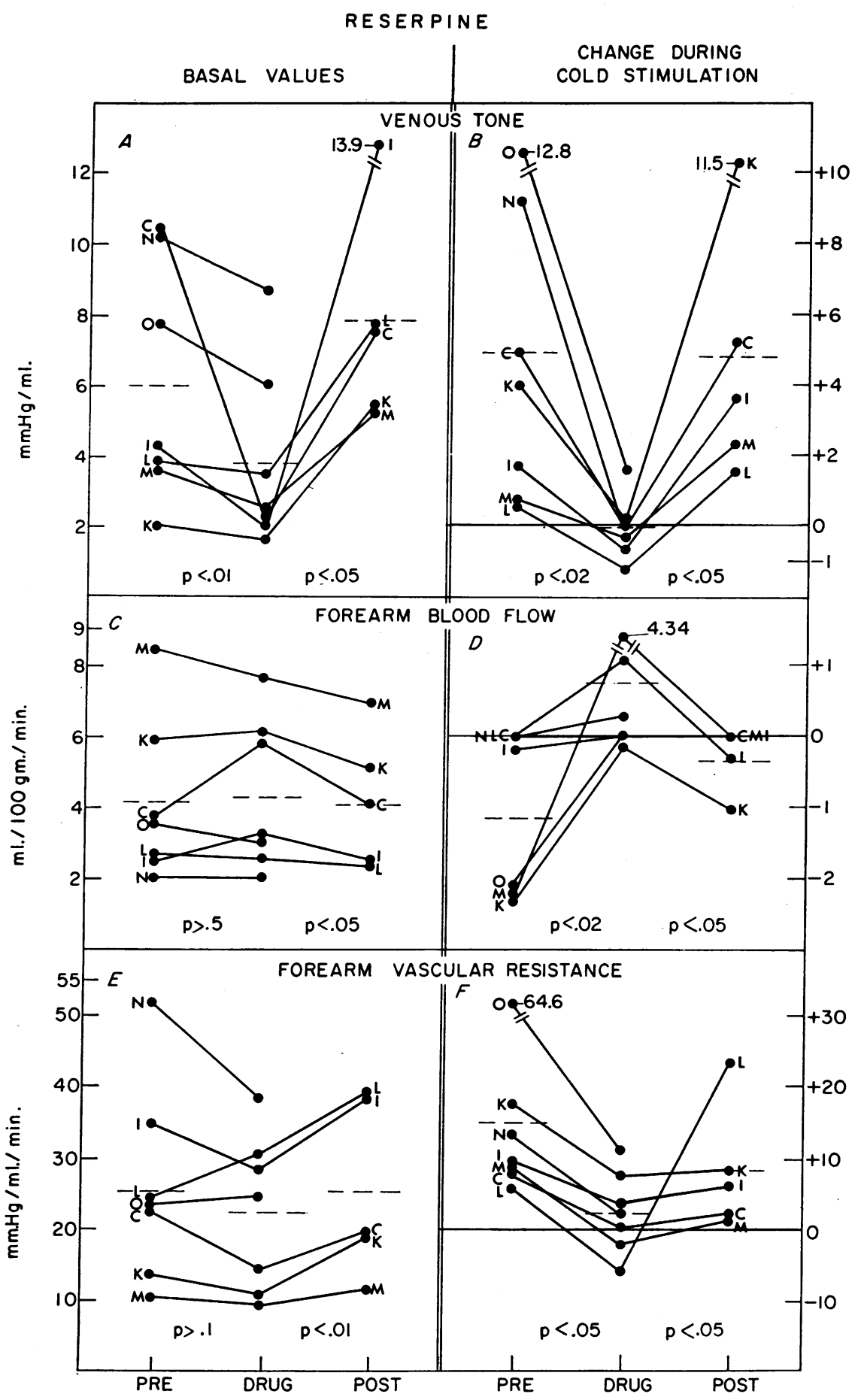

Fig. 6. RESUlts OF OBSERVATIONS MAdE BEFORE, DURING, AND AFTER RESERPINE ADMinistration. For explanation, see legend to Figure 3. 
The maximal post-Valsalva systolic arterial pressure overshoot averaged $23 \pm 2.1 \mathrm{~mm} \mathrm{Hg}$ during the predrug control study. The overshoot was almost abolished and significantly lower ( $p<0.01$ ) during the drug study, at which time it averaged $0.5 \pm 0.4 \mathrm{~mm} \mathrm{Hg}$, and had risen to $15 \pm 2.7 \mathrm{~mm} \mathrm{Hg}$ at the time of the postdrug control study.

Reserpine. The mean systemic arterial pressure averaged $84 \pm 3.9 \mathrm{~mm} \mathrm{Hg}$ during the predrug control study, $77 \pm 1.0 \mathrm{~mm} \mathrm{Hg}$ during the drug study, and $85 \pm 3.1 \mathrm{~mm} \mathrm{Hg}$ during the postdrug control study. The resting heart rate averaged $74 \pm 1.7$ per minute during the control study. It was significantly slower, $61 \pm 2.3$ per minute ( $p<0.01)$, during the drug study. At the time of the postdrug control study the heart rate was significantly more rapid, averaging $76 \pm 2.9$ per minute $(\mathrm{p}<0.01)$.

When measured by the acute occlusion technique in the basal state, the venous tone averaged $6.0 \mathrm{~mm} \mathrm{Hg}$ per $\mathrm{ml}$ during the predrug control study. It declined significantly $(p<0.01)$ to an average value of $3.8 \mathrm{~mm} \mathrm{Hg}$ per ml during the drug study. In the postdrug study the average venous tone equaled $7.9 \mathrm{~mm} \mathrm{Hg}$ per $\mathrm{ml}$ and was significantly $(p<0.05)$ greater than when the subjects were receiving reserpine (Figure 6A). During the drug study the change in venous tone during cold immersion was significantly less $(p<0.02)$ than during the predrug control study. In the postdrug control study venoconstriction again occurred during cold immersion in all 5 subjects tested (Figure 6B).

In the 2 subjects receiving reserpine in whom venous tone was determined by the equilibration techniques, increases in venous tone occurred during cold immersion in the predrug control study, but these increases were found to have been completely or almost completely abolished during the drug study (Figures 4 and 5 ). In the 2 subjects in whom the effects of leg exercise on venous tone were determined by the acute occlusion technique, increases of venous tone of 2.3 and $2.7 \mathrm{~mm} \mathrm{Hg}$ per $\mathrm{ml}$ occurred during the predrug control study. During the drug studies venous tone fell by 1.2 $\mathrm{mm} \mathrm{Hg}$ per $\mathrm{ml}$ in 1 subject and did not change in the other during leg exercise.

In the postdrug control study the forearm blood flow was slightly, but significantly, smaller $(p<$
0.05) (Figure 6C), and the forearm vascular resistance was slightly but significantly greater than during the drug study $(\mathrm{p}<0.01)$ (Figure $6 \mathrm{E}$ ). During cold immersion forearm blood flow diminished less, and forearm vascular resistance increased significantly less in the course of the drug study than during either the pre- or postdrug control studies (Figure 6D and F). The maximal post-Valsalva systolic arterial pressure overshoot averaged $25 \pm 6.9 \mathrm{~mm} \mathrm{Hg}$ during the predrug control study. It was reduced significantly $(\mathrm{p}<$ 0.05 ) to an average of $9 \pm 2.2 \mathrm{~mm} \mathrm{Hg}$ when measured in the drug study and had returned to an average value of $19 \pm 3.5 \mathrm{~mm} \mathrm{Hg}$ during the postdrug control study.

Methyldopa. The mean systemic arterial pressures averaged $95 \pm 4.5 \mathrm{~mm} \mathrm{Hg}$ during the predrug control study, $98 \pm 17.7 \mathrm{~mm} \mathrm{Hg}$ during the drug study, and $97 \pm 3.5 \mathrm{~mm} \mathrm{Hg}$ during the postdrug study. The resting heart rate, which averaged $75 \pm 3.0$ per minute during the predrug control study, was significantly lower $(p<0.05)$ during the drug study, when it averaged $66 \pm 3.8$ per minute, and rose significantly $(\mathrm{p}<0.02)$ to $81 \pm$ 2.7 per minute at the time of the postdrug control study.

During the drug study the increase in venous tone that occurred during cold immersion was abolished (Figure 7B), and in the postdrug control study it was significantly greater $(p<0.01)$ than during the drug study. In the 2 subjects in whom venous tone was measured by the equilibration techniques, increases occurred during ice water immersion in the predrug control studies, and these responses were found to be completely abolished during the drug study (Figures 4 and $5)$. In the subject in whom the effects of leg exercise on venous tone were determined by the acute occlusion technique, increases of 3.1 and $2.8 \mathrm{~mm} \mathrm{Hg}$ per $\mathrm{ml}$ occurred during the predrug and postdrug control studies, respectively. However, no change in venous tone occurred when he exercised at the time of the drug study.

During both control periods cold immersion generally resulted in a decline in forearm blood flow (Figure 7D) and an augmentation of forearm vascular resistance (Figure 7F). During the drug study, cold immersion failed to diminish blood flow (Figure 7D), and only a small increase in forearm vascular resistance occurred (Figure 


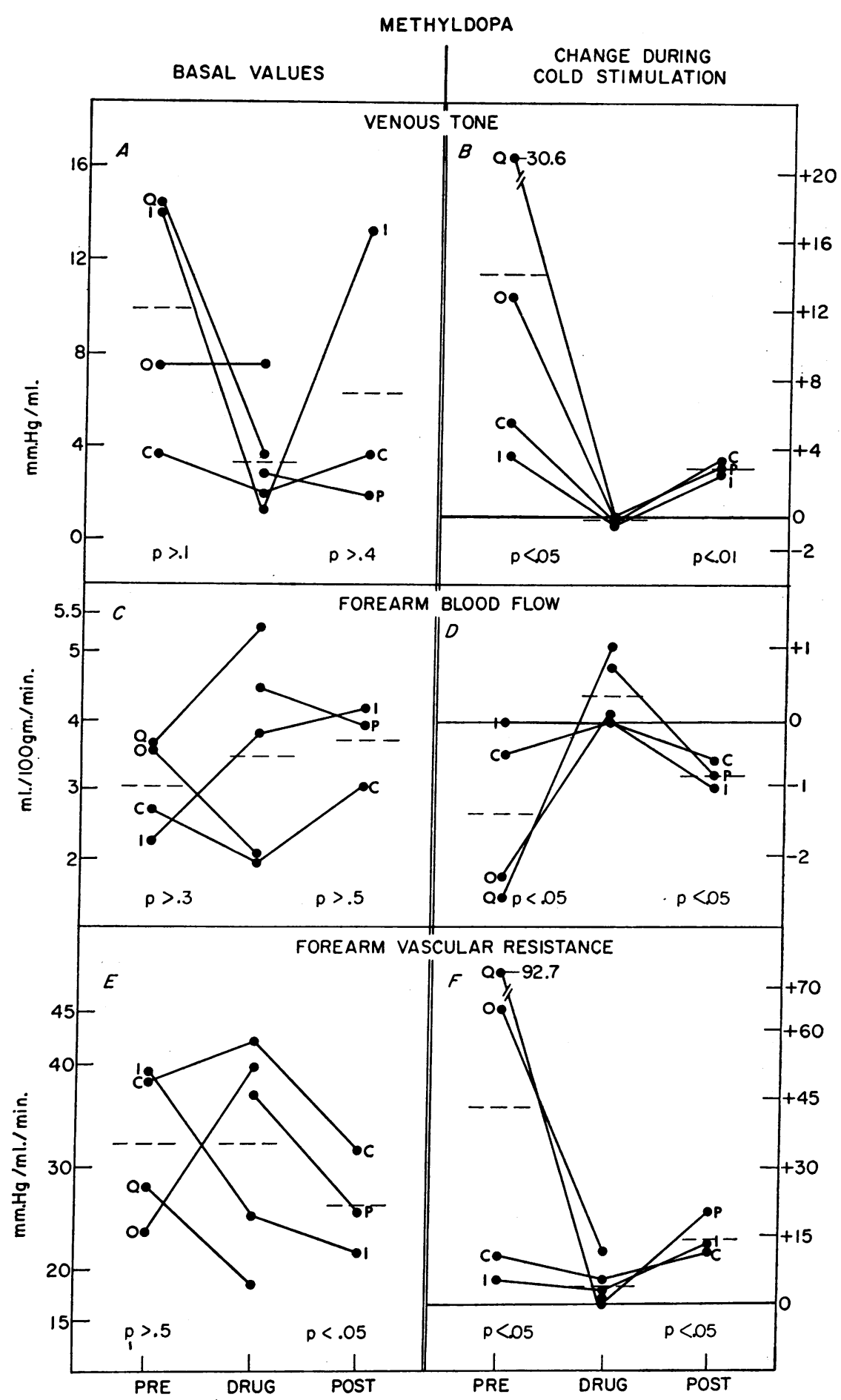

Fig. 7. RESUltS OF OBSERVATIONS MADE BEFORE, DURING, AND AFTER METHYLDOPA administration. For explanation, see legend to Figure 3. 
7F). The maximal post-Valsalva systolic arterial pressure overshoot averaged $35 \mathrm{~mm} \mathrm{Hg}$ during the predrug control study. It was completely abolished in every subject during the drug study and had risen to an average of $32 \mathrm{~mm} \mathrm{Hg}$ at the time of the postdrug control study.

Although both postural hypotension and blockade of reflex venoconstriction were observed in the course of every single drug study, there was no direct correlation between the absolute magnitude of the changes in each of these two variables.

Atropine. The effects of $2.0 \mathrm{mg}$ atropine, given intravenously, were studied in 4 of the subjects who, at the time of the drug study, exhibited a decline in venous tone during cold immersion or leg exercise. Two of these subjects were receiving guanethidine, 1 was receiving reserpine, and 1 , methyldopa. The response of venous tone to cold immersion was restudied in all 4 subjects after atropine, and the response to leg exercise was determined in 2 subjects. In each instance the paradoxical decline in venous tone was either abolished or markedly reduced (Figure $8 \mathrm{~A}$ and $\mathrm{B}$ ).

\section{Discussion}

After the introduction of the ganglionic blocking agents for the treatment of systemic arterial

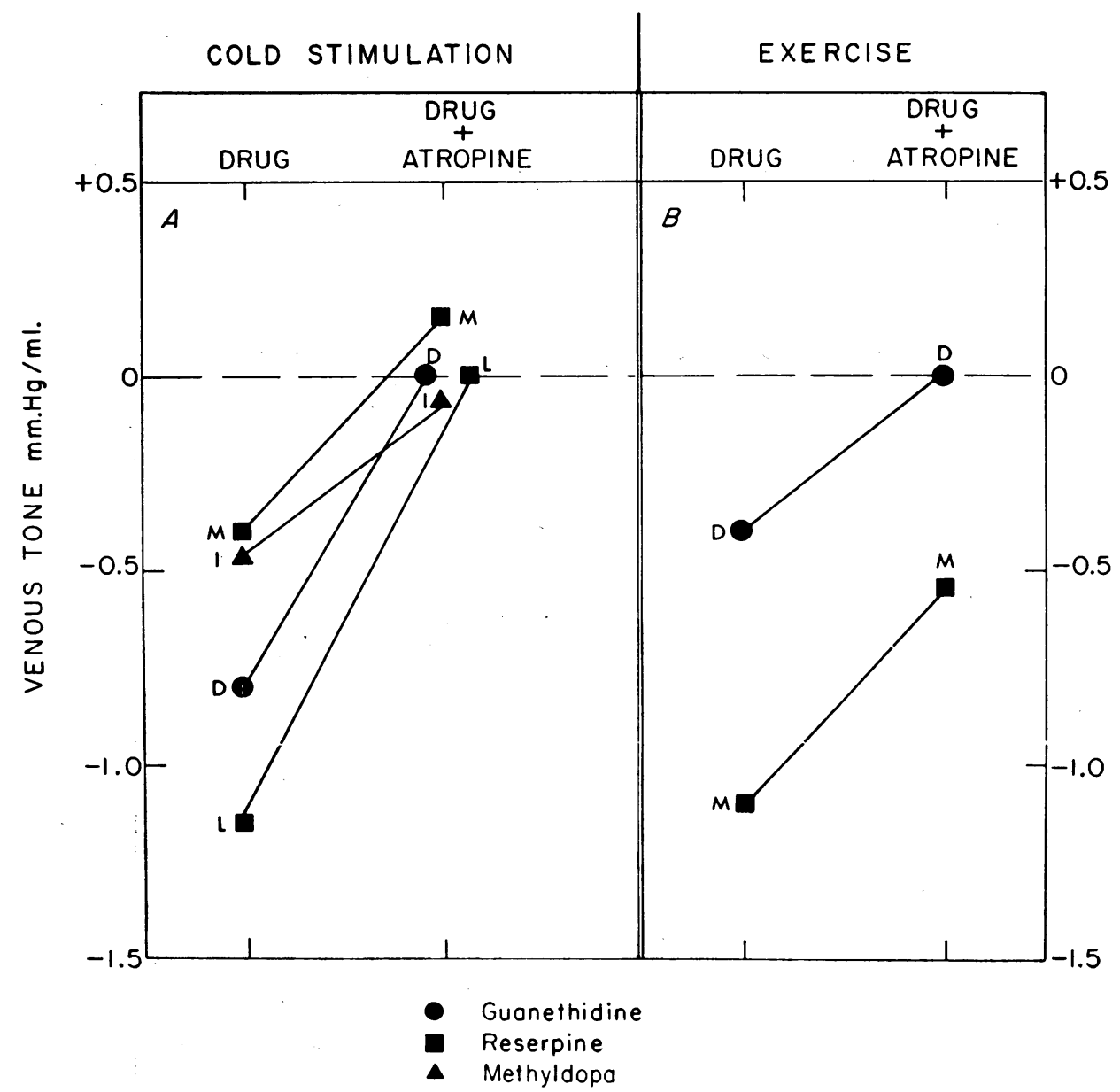

Fig. 8. A. EfFect of cold immersion on venous tone while the SUbJects Were ReCEIVING ONE OF THE ANTIADRENERGIC DRUGS (LEFT) AND IMMEDIATELY AFTER RECEIVING ATROPINE (RIGHT). The decline in venous tone occurring during cold immersion when the subjects were on the antiadrenergic drugs is prevented by atropine. B. EFFECTS OF LEG EXERCISE ON VENOUS TONE BEFORE AND AFTER ATROPINE. Note that in comparison to the other figures, the ordinate scale in this figure is greatly expanded. 
hypertension, a number of investigators observed that these drugs do not usually lower the calculated systemic vascular resistance but that the decline in arterial pressure which is induced generally accompanies a fall in cardiac output (7-10). These observations suggested that the ganglionic blocking agents act upon the venous system, the fall in cardiac output being attributed to a decreased venous return due to failure of normal reflex venoconstriction (5). Similarly, Richardson, Wyso, Magee, and Cavell, observing only small decreases in systemic vascular resistance after the administration of guanethidine, suggested the possibility that like the ganglionic blocking drugs, guanethidine lowers arterial pressure by reducing cardiac output, possibly by inhibiting sympathetic venoconstrictor mechanisms (11). Direct evidence to support the view that reflex venoconstriction can actually be blocked by guanethidine and reserpine was provided by experiments in which relatively large, parenteral doses of these drugs were used in acute experiments in dogs (6).

The present investigation showed that the chronic oral administration of these two drugs and of methyldopa to human subjects prevents or nearly abolishes the increase in forearm venous tone that occurs during cold stimulation and leg exercise. Other investigators have previously established that these two stimuli are capable of inducing venoconstriction in man $(17,19-24)$. On the other hand, these drugs resulted in only small decreases in forearm venous tone when this variable was measured in the basal state. In the latter condition the veins are probably dilated already (17), and pharmacologic blockade of venoconstrictor impulses therefore might not be expected to have a profound effect on basal venous tone. The observation that the marked augmentation of venous tone resulting from cold immersion or exercise was essentially prevented by these drugs, while there was relatively little effect on the basal venous tone, is also in accord with the observation that the arterial pressure remained unchanged or fell only slightly in the supine position, at a time when all of the subjects exhibited significant postural hypotension. The loss of forearm venoconstriction during leg exercise induced by the drugs studied may also help to explain the finding that muscular exercise re- sults in a paradoxical decline in systemic pressure in patients undergoing treatment with guanethidine (25). Although all three drugs were effective in blocking reflex venoconstriction, it is notable that the duration of the administration of reserpine exceeded that of guanethidine, and the doses of methyldopa employed were relatively large, correlating with the greater antihypertensive potency of guanethidine in relation to that of the other two drugs. In some instances, the values of venous tone, and the alterations of venous tone during cold stimulation observed in the postdrug control study had not returned to the levels at the time of the predrug control study. These differences are likely related to residual effects of the drugs, but no clear correlation between the time interval from the discontinuance of the drug and the magnitude of the values at the time of the postcontrol study was evident.

In a number of the subjects the increase in venous tone during cold stimulation and exercise was not only abolished in the course of the drug studies, but a paradoxical decline in venous tone occurred. That selective activation of the sympathetic cholinergic fibers can result in arteriolar dilation is well known (26-28). The possibility was therefore considered that the paradoxical venodilation resulted from activation of sympathetic cholinergic venodilator fibers at a time when the drug had blocked the adrenergically mediated venoconstriction. This hypothesis was supported by studying with atropine the effects of cholinergic blockade. Although the absolute changes produced were small, the intravenous administration of atropine to 4 subjects either abolished or reduced the paradoxical reflex venodilation present when only the antiadrenergic agent had been administered (Figure 8).

None of the three drugs affected forearm blood flow or calculated forearm resistance when measured in the basal state. However, the declines in forearm blood flow that occurred during cold stimulation and leg exercise in the pre- and postdrug control studies were not observed when the patients were receiving the medications (Figures 3,6 , and 7). Similarly, calculated forearm vascular resistance increased as a result of leg exercise and cold immersion in the control studies, and the antihypertensive drugs resulted in a reduction and abolition or a reversal of these responses. 
The three drugs studied likely also affected the activity of the cardiac autonomic nerves, since in each instance the basal heart rate was significantly lower during the drug study than during either the pre- or postdrug control studies. These findings correlate with the observations that the oral administration of $0.5 \mathrm{mg}$ reserpine for 6 weeks results in essentially complete depletion of myocardial norepinephrine stores in patients (29) and that the withdrawal of sympathetic stimulation of the heart by guanethidine may intensify the heart failure state (30).

In conclusion, the present investigation showed that guanethidine, reserpine, and methyldopa, when given to normal subjects in the usual clinical doses, interfere with reflex constriction of both the arterial and venous beds in the forearm, and result in slowing of the heart. Interference with release or depletion of the sympathetic neurotransmitter is likely responsible for all of these effects, and the antihypertensive actions of these drugs probably do not result solely from their effects upon the arteriolar bed. It must be emphasized, however, that the studies reported were carried out in normal subjects rather than in patients with essential hypertension and that application of the present findings to patients with hypertension are of necessity speculative.

\section{Summary}

The effects of guanethidine, reserpine, and methyldopa on the venous and arteriolar beds of the forearm were studied in 17 normal subjects. During the control period profound reflex venoconstriction was elicited by immersion of the opposite hand in ice water and by leg exercise. These reflex venopressor responses to ice water and exercise were abolished or almost completely inhibited in 10 subjects who received 30 to $50 \mathrm{mg}$ per day of guanethidine orally for 26 to 43 days, in 7 subjects given $0.5 \mathrm{mg}$ per day of reserpine for 35 to 132 days, and in 5 subjects given 2.0 to $5.0 \mathrm{~g}$ per day of methyldopa for 21 to 49 days. In addition, these drugs also decreased reflex arteriolar constriction. When the drugs were discontinued, the reflex constriction of the venous and arteriolar beds to cold immersion and exercise returned. Therefore, these antihypertensive drugs, in the usual clinical doses, are evidently capable of blocking reflex venoconstriction. Venous return is likely decreased by this action, and the resultant reduction of cardiac output contributes to the hypotensive effects observed in patients undergoing treatment with these drugs.

\section{Acknowledgment}

The collaboration of Dr. Thomas E. Gaffney in the planning of this study is gratefully acknowledged.

\section{References}

1. Landis, E. M., and J. C. Hortenstine. Functional significance of venous blood pressure. Physiol. Rev. 1950, 30, 1.

2. Alexander, R. S. The participation of the venomotor system in pressure reflexes. Circulat. Res. 1954, 2, 405.

3. Heymans, C., and E. Neil. Reflexogenic Areas of the Cardiovascular System. Boston, Little, Brown, 1958.

4. Ross, J., Jr., C. J. Frahm, and E. Braunwald. Influence of carotid baroreceptors and vasoactive drugs on systemic vascular volume and venous distensibility. Circulat. Res. 1961, 9, 75.

5. Braunwald, E., J. Ross, Jr., R. L. Kahler, T. E. Gaffney, A. Goldblatt, and D. T. Mason. Reflex control of the systemic venous bed: effects on venous tone of vasoactive drugs, and of baroreceptor and chemoreceptor stimulation. Circulat. Res. 1963, 12, 539.

6. Gaffney, T. E., W. M. Bryant, and E. Braunwald. Effects of reserpine and guanethidine on venous reflexes. Circulat. Res. 1962, 11, 889.

7. Werko, L., A. R. Frisk, G. Wade, and H. Eliasch. Effect of hexamethonium bromide in arterial hypertension. Lancet 1951, 2, 470.

8. Freis, E. D., J. C. Rose, E. A. Partenope, T. F. Higgins, R. T. Kelley, H. W. Schnaper, and R. L. Johnson. The hemodynamic effects of hypotensive drugs in man: III. Hexamethonium. J. clin. Invest. 1953, 32, 1285.

9. Smith, J. R., and S. W. Hoobler. Acute and chronic cardiovascular effects of pentolinium in hypertensive patients. Circulation 1956, 14, 1061.

10. Restall, P. A., and F. H. Smirk. Regulation of blood pressure levels by hexamethonium bromide and mechanical devices. Brit. Heart J. 1952, 14, 1.

11. Richardson, D. W., E. M. Wyso, J. H. Magee, and G. C. Cavell. Circulatory effects of guanethidine. Clinical, renal, and cardiac responses to treatment with a novel antihypertensive drug. Circulation 1960, 22, 184.

12. McCubbin, J. W. The clinical and experimental pharmacology of guanethidine. Med. Clin. N. Amer. 1961, 45, 409. 
13. Mason, D. T., and E. Braunwald. Studies on digitalis. X. Effects of ouabain on forearm vascular resistance and venous tone in normal subjects and in patients in heart failure. J. clin. Invest. 1964, 43, 532.

14. Whitney, R. J. The measurement of volume changes in human limbs. J. Physiol. (Lond.) 1953, 121, 1.

15. Holling, H. E., H. C. Boland, and E. Russ. Investigation of arterial obstruction using a mercury-in-rubber strain gauge. Amer. Heart J. 1961, 62, 194.

16. Sharpey-Schafer, E. P. Venous tone. Brit. Med. J. 1961, 2, 1589.

17. Wood, J. E., and J. W. Eckstein. A tandem forearm plethysmograph for study of acute responses of the peripheral veins of man: the effect of environmental and local temperature change, and the effect of pooling blood in the extremities. J. clin. Invest. 1958, 37, 41.

18. Mainland, D. Elementary Medical Statistics. Philadelphia, W. B. Saunders, 1952, p. 154.

19. Duggan, J. J., V. L. Love, and R. H. Lyons. A study of reflex venomotor reactions in man. Circulation 1953, 7, 869.

20. Page, E. B., J. B. Hickam, H. O. Sieker, H. D. McIntosh, and W. W. Pryor. Reflex venomotor activity in normal persons and in patients with postural hypotension. Circulation 1955, 11, 262.

21. Ross, J. C., J. B. Hickam, W. P. Wilson, and H. Lowenbach. Reflex venoconstrictor response to strong autonomic stimulation. Amer. Heart J. 1959, 57, 418.

22. Merritt, F. L., and A. M. Weissler. Reflex venomotor alterations during exercise and hyperventilation. Amer. Heart J. 1959, 58, 382.

23. Wood, J. E., and D. E. Bass. Responses of the veins and arterioles of the forearm to walking during acclimatization to heat in man. J. clin. Invest. 1960, 39, 825.

24. Burch, G. E. Influence of the central nervous system in veins in man. Physiol. Rev. 1960, 40 (suppl. 4, part II), 50.

25. Leishman, A. W. D., H. L. Matthews, and A. J. Smith. Guanethidine, hypotensive drug with prolonged action. Lancet 1959, 2, 1044.

26. Uvnäs, B. Sympathetic vasodilator outflow. Physiol. Rev. 1954, 34, 608.

27. Uvvnäs, B. The vasodilator nerves. Amer. Heart J. 1961, 62, 277.

28. Shepherd, J. T. Physiology of the Circulation in Human Limbs in Health and Disease. Philadelphia, W. B. Saunders, 1963, p. 64.

29. Chidsey, C. A., E. Braunwald, A. G. Morrow, and D. T. Mason. Myocardial norepinephrine concentration in man: effects of reserpine and of congestive heart failure. New Engl. J. Med. 1963, 269, 653.

30. Gaffney, T. E., and E. Braunwald. Importance of the adrenergic nervous system in the support of circulatory function in patients with congestive heart failure. Amer. J. Med. 1963, 34, 320. 